\title{
EVALUATION OF OPERATIONAL AND ENVIRONMENTAL PERFORMANCE OF MEDIAN U-TURN DESIGN USING MICRO- SIMULATION
}

\author{
Ibrahim H. Hashim', Mohamed Ragab ${ }^{2}$, Gaber M. Asar ${ }^{3}$ \\ ${ }^{1}$ Department of Civil Engineering, Faculty of Engineering, Menoufia University, Egypt \\ ${ }^{2}$ Department of Civil Engineering, Higher Institute of Engineering and Technology in Kafr El-Sheikh \\ ${ }^{3}$ Department of Mechanical Engineering, Faculty of Engineering, Menoufia University, Egypt
}

Received 20 June 2016; accepted 23 August 2016

\begin{abstract}
Road intersections force vehicles to slow down and stop in varying patterns and contribute to the increase in vehicular emissions. The main aim of this paper is to evaluate the operational and environmental performance of median U-turn design. Also, it aims to compare this design with conventional three-leg and signalized three-leg intersections in terms of average delay, fuel consumption and air emissions including carbon monoxide (CO), nitrogen oxides $\left(\mathrm{NO}_{\mathrm{X}}\right)$ and hydrocarbons $(\mathrm{HC})$. The microscopic traffic simulation model VISSIM was used to model and analyze the three designs under a wide range of balanced and unbalanced flow conditions. The results indicated that, the median U-turn (MUT) design exhibited slightly lower delays than conventional three-leg intersection at balanced volume scenarios, up to approximately $1250 \mathrm{veh} / \mathrm{hr} / \mathrm{approach}$. After this volume level, the median U-turn (MUT) design exhibited higher delays than three-leg intersection. Also, the median U-turn (MUT) design exhibited lower air emissions and fuel consumption than other intersections at all balanced volume scenarios. In addition, under unbalanced volume scenarios, the average delay, air emissions and fuel consumption increased with the increase of main and/or cross street volumes for the median U-turn (MUT) design.
\end{abstract}

Keywords: air emissions, median U-turn, three-leg intersection, traffic simulation.

\section{Introduction}

Road intersections play an important role in the overall performance of road network. They involve the highest traffic density, the longest vehicle idling time, and the most deceleration and acceleration rates. They are often "hot spots" of air pollution and have negative environmental and health impacts on vital buildings such as hospitals and schools in the vicinity (Lv, 2012). Thus, the demand for more efficient intersection designs is a high priority. There are different types of intersections, but the three-leg (T) intersection is the most common intersection design in Egypt.

The median U-turn (MUT) is the most common unconventional intersection design in many countries today, as there are many advantages associated with the elimination of direct left-turns at intersections. For instance, it may improve the capacity of the intersection and reduce the number of

\footnotetext{
${ }^{2}$ Corresponding author: mohamedragab@sh-eng.menofia.edu.eg
} 
stops for through traffic. Using U-turns as alternatives to direct left-turns reduces the number of conflict points, thereby improving the safety performance of the intersection. Furthermore, intersections without direct left-turn may reduce the total travel time of the intersection, which will result in less consumption of fuel, therefore, less pollution.

In Egypt, before the implementation of the MUT design, intersections were operated by the local traffic police force. The number of intersections has increased significantly with the construction of new roads. Nonetheless, the number of the traffic police force men is insufficient to operate all intersections. Therefore, Highway authorities in Egypt found no other solution rather than forcing certain movements at the intersection using physical barriers to enforce traffic laws (El Esawy and Sayed, 2011).

Delay time is the most significant measureof-effectiveness that is extensively used in operational performance evaluation at any intersection analysis. Delay is the time lost while traffic is impeded by elements over which the driver has no control (HCM, 2010).

Traffic congestion, especially at intersections, affects the environment because vehicles slow down and almost stop when stuck in a bottleneck; therefore, creating more fuel emissions. Another problem is the fuel consumption, if vehicles stay more time on the roads due to congestion, then they will use more fuel and that affects the environment. Emission levels depend also on the change in speed and acceleration of vehicles within a traffic stream. These emissions have adverse effects on the environment and subsequently on the overall human health (El-Metwally and Rakha, 2009).
Road traffic is one the major sources of air emissions. Air emissions due to road traffic include nitrogen oxides, carbon monoxide and volatile organic compounds. Carbon monoxide (CO) is formed during combustion when there is insufficient oxygen to oxidize the fuel fully. $\mathrm{CO}$ is a potentially dangerous emission and gasoline engines contribute more than $90 \%$ of the total emissions. In urban areas, $\mathrm{CO}$ concentrations follow a diurnal pattern, which mainly depends on traffic volume. Nitrogen oxides $\left(\mathrm{NO}_{\mathrm{X}}\right)$ are released into the atmosphere by automobile exhausts especially diesel engines. Nitric oxide (NO) is the main emission from automobiles. Nitric oxide is converted into nitrogen dioxide $\left(\mathrm{NO}_{2}\right)$ by reaction with oxidants presents in ambient air. Hydrocarbon (HC) are chiefly released into the atmosphere by automobile exhausts especially automobiles using petrol. Hydrocarbon components due to automobile exhaust are mainly Ethylene, Acetylene and Benzene (Srinivasan et al., 1979).

Fuel consumption can be characterized by a time-dependent instantaneous rate with respect to location along the roadway. Fuel consumption for any vehicle traveling along the roadway actually depends on the vehicle type, vehicle condition, and traffic conditions (Liao and Machemehl, 1995).

Nowadays, operational and environmental impact assessment of any project is fundamental before proceeding to any implementation of any designs (Olarte, 2011). Therefore, in this study, the operational and environmental analysis will be carried out using the micro-simulation platform VISSIM V. 7.00 (PTV AG, 2014) software to determine the average delays and to measure the levels of vehicle air emissions due to median U-turn design and traffic 
volumes for three-leg intersection. Average delay is used to measure the operational performance of the intersection whereas vehicle fuel consumption and different vehicle air emissions including carbon monoxide $(\mathrm{CO})$, nitrogen oxides $\left(\mathrm{NO}_{\mathrm{X}}\right)$ and hydrocarbons (HC) were used to measure the environmental performance of the intersection.

The paper starts with a brief introduction followed by previous studies. The third section illustrates the methodology of the study. The results of the analysis are presented in section four. Finally, conclusions are presented in section five.

\section{Previous Studies}

Many years ago, the concerns with emissions at an intersection could be found in the EPA reports (Environmental Protection Agency (EPA), 1975; Midurski and Corbin, 1976). There have been many studies on intersection emissions since then. However, most of them computed emissions based on stops, delay, or queue length from macroscopic modeling of traffic. For instance, (Tarnoff and Parsonson, 1979) translated emissions and fuel consumption from vehicle stops and delay when demonstrating the potential environmental benefits at intersections.

Many studies investigated the operational and environmental performance of different intersection types. In a study conducted by (Mustafa et al., 1993), the authors investigated the relationship between vehicle emissions and traffic volumes at urban intersections. The results of simulation showed that, traffic signals generate air emissions 50\% higher than roundabouts.
(Niittymaki, 1999) carried out a study to evaluate the environmental performance of intersection designed as a roundabout instead of using traffic signals. The results of analysis showed that, there is a $30 \%$ reduction of fuel consumption.

Results of a study conducted by (Varhelyi, 2002) in Sweden, showed that replacing a signalized intersection by a roundabout resulted in an average decrease in $\mathrm{CO}$ emissions by $29 \%, \mathrm{NO}_{\mathrm{X}}$ emissions by $21 \%$ and fuel consumption by $28 \%$ per vehicle.

(Bared and Kaisar, 2002) used CORSIM software to analyze a MUT intersection with signalized crossovers added to the main road. The study concluded that, under balanced volumes, there is a significant overall travel time reduction of the MUT design compared to the conventional intersection.

(Yang and Zhou, 2004) evaluated the operational performance of direct left turn and right turn plus U-turn from driveways under different levels of traffic volumes using CORSIM software. They used the delay and travel time as a Measures of Effectiveness (MOEs) for the study. The simulation results showed that, direct left-turn exhibited lower travel time and delay than right turn plus U-turn at lower level of through-traffic volume on the major road. But, with an increase in the through volume, direct leftturn exhibited higher travel time and delay than right turn plus U-turn.

(Mandavilli et al., 2008) used SIDRA software to analyze the environmental impact of roundabouts. Roundabout has replaced stop-controlled intersection in six sites with different traffic volume ranges. 
$\mathrm{HC}, \mathrm{CO}, \mathrm{NO}_{\mathrm{x}}$, and $\mathrm{CO}_{2}$ emissions have been chosen as a Measures of Effectiveness (MOEs) for the study. They concluded that, roundabouts performed better than stopcontrolled intersections.

(Taha and Abdelfatah, 2015) used VISSIM software to evaluate the operational effects of three left-turn control types including direct left-turn, right-turn followed by U-turn, and U-turn followed by right-turn. The results of this study proved that, unconventional left-turn control types could have better operational performance than direct leftturns, under most of traffic conditions.

\section{Methodology}

The proposed methodology of this study consists of the following subsections. The first section describes the software used to model and analyze the intersections. Next, the geometric characteristics and the input parameters for each model required for the simulation analysis are described. Then, the traffic demand data will be presented with the hypothetical data for the study. Lastly, it is important to note what parameters will be used to compare the operational and environmental performance of different intersection designs.

\subsection{Simulation Platform}

In this study the micro-simulation platform VISSIM will be used to analyze the performance of conventional threeleg, signalized three-leg and three-leg with median U-turn intersections. VISSIM is a microscopic simulation model that was developed by German company Planung Transport Verkher (PTV) Vision Suite. This software has the ability to simulate multimodal traffic flows including cars, trucks, buses, etc. It has a versatile network structure that gives the users the capability of building models with any type of geometric features and has the ability to model unconventional schemes. Also, it has been used to analyze small intersections as well as big networks and its many applications include but are not limited to freeway and arterial corridor studies, sub-area planning, environmental impact studies and even Intelligent Transportation Systems (ITS) assessments (PTV AG, 2014).

Moreover, VISSIM lets the users choose how they want to see the outputs of the evaluations. For example, the user can select from a variety of measures of effectiveness including average delay, fuel consumption and air emissions (Gyawali, 2014).

\subsection{Geometric Characteristics}

In order to achieve the objectives of this study, it is important to know the geometric characteristics of the intersection designs. Fig. 1 depicts the geometric characteristics of the analyzed conventional three-leg and three-leg with median U-turn intersections. Thus, in order to compare the three intersection designs; the conventional threeleg, signalized three-leg and median U-turn intersections, the following parameters were kept constant:

- Each of the three approaches had the same number of lanes, two lanes;

- Lane widths were set to $3.5 \mathrm{~m}$ with no sidewalks.

It is important to mention that, for the median U-turn (MUT) design the distance between the main and the secondary intersection is determined according to the FHWA informational guide (Rodegerdts 
et al., 2004). The optimal distance for placing the U-turn crossover is $170 \mathrm{~m}$ to $230 \mathrm{~m}$ from the primary intersection for MUT designs. Therefore, in this study, the distance between the primary intersection and the U-turn crossover was selected to be $200 \mathrm{~m}$. Also, exclusive storage bays of $65 \mathrm{~m}$ in length were added before and after the U-turn crossovers.

\subsection{Traffic Demand}

The traffic demand data for this study was generated hypothetically with values ranging from low to high to simulate peak and off-peak traffic. Thus, the volumes were also designed under balanced and unbalanced conditions to allocate any traffic fluctuations that might affect the study. In addition to this, the percentage of right-turn traffic was set to $10 \%$ for all scenarios. Also, to quantify the effect of increasing left turn volume on the average delay, air emissions and fuel consumption of median U-turn design, two different levels of left turn volume were simulated, representing $20 \%$ and $30 \%$ of the total approach volume for the balanced scenarios as shown in Fig. 2. The impact of heavy vehicles percentage on the performance of median U-turn design was considered by modeling all volume scenarios with $2 \%$ and $5 \%$ heavy vehicles while maintaining the same approach volume for the balanced conditions. The hypothetical values for the volumes were varied from 500 to $1200 \mathrm{veh} /$ $\mathrm{hr} / \mathrm{approach}$ with $100 \mathrm{veh} / \mathrm{hr} / \mathrm{approach}$ increments. Additional runs were simulated until the traffic flow output of the model reached its maximum.

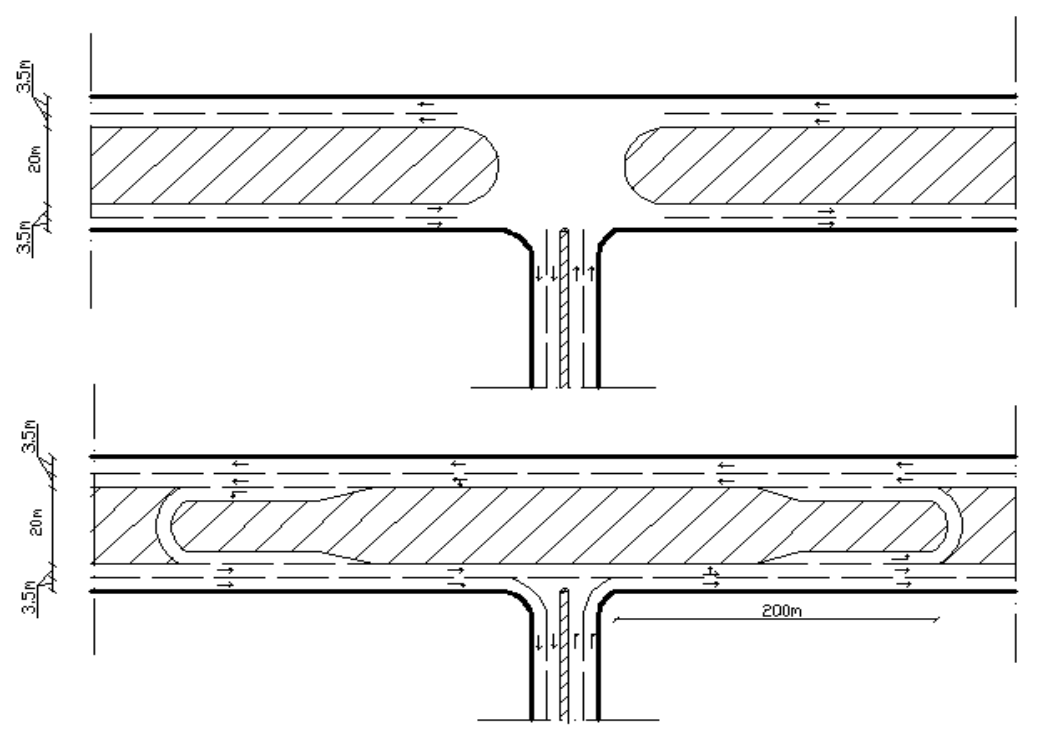

Fig. 1.

Geometric Characteristics of the Analyzed Conventional Three-leg and Three-leg with Median U-turn Intersections (not to scale) 


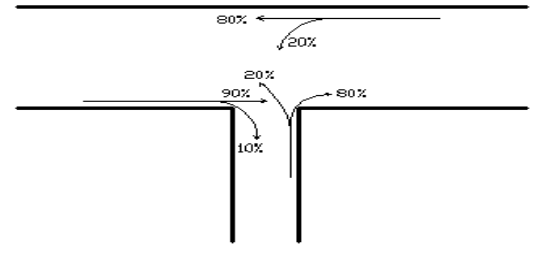

20\% Left-turn

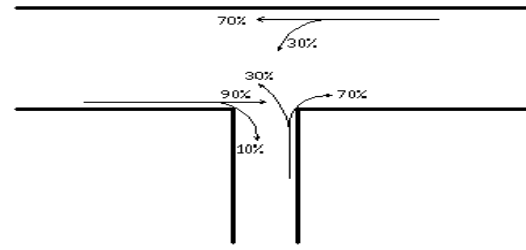

30\% Left-turn

Fig. 2.

Right-Turn and Left-Turn Percentages of Three-leg Intersection

\subsection{Simulation Characteristics}

The micro simulation software VISSIM V. 7.00 (PTV AG, 2014) was used to create all the models. Some general parameters of this software were kept at their default values and the driver characteristics were not changed either. VISSIM was selected because it allows lane by lane development of road networks. This facilitated the construction of the unconventional intersections exactly as they would appear in real life. Additionally, VISSIM has been extensively used before in analyzing unconventional intersections. The Wiedemann 74-car following model was selected in VISSIM for vehicle behavior, and, in general, default driving parameters were used. All vehicles targeted a speed of $50 \mathrm{~km} / \mathrm{hr}$.
Once the traffic demand volumes were generated hypothetically, they were input in the software for each model and it generated a total of 10 simulation runs for every intersection design at balanced condition with $20 \%$ left turn and $2 \%$ heavy vehicles. Also, it generated a total of 20 simulation runs for median U-turn at balanced condition with $30 \%$ left turn and $5 \%$ heavy vehicles. Then, it generated a total of 64 simulation runs for median U-turn at unbalanced condition with $20 \%$ left turn and $2 \%$ heavy vehicles. Moreover, each run was a total of one hour long with a warm up period of 600 seconds. For signalized three-leg intersection, three phases were used, as shown in Fig. 3. Also, a pre timed signal controller with three seconds amber was used for all signals.

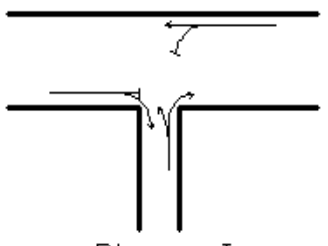

Phase I

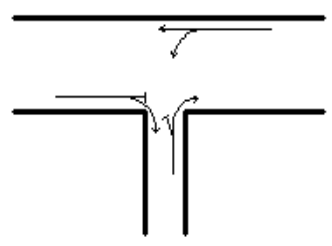

Phase II

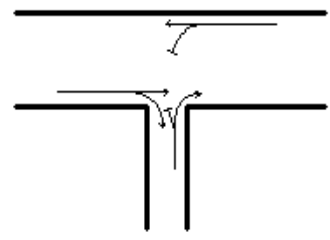

Phase III

Fig. 3.

Three Phases of Three-leg Intersection 


\subsection{Measures of Effectiveness}

For the evaluation and comparison of the intersections in this study, several aspects were considered to define the measures of effectiveness. The performance measures will be defined according to what the software specifies. For instance, delay is a typical parameter used to measure the performance of the intersection. This measure is often utilized to define the level of service and the operational performance of the intersection. VISSIM defines average total delay, in seconds per vehicle, as the difference between the desired travel time and actual travel time. There are also some factors relevant for the evaluation of the models such as vehicle fuel consumption and different vehicle air emissions including carbon monoxide (CO), nitrogen oxides $\left(\mathrm{NO}_{\mathrm{X}}\right)$ and hydrocarbons (HC). These factors can be used as measures of effectiveness for the environmental analysis of the intersection designs.

Therefore, in this study, average delay in seconds per vehicle, average fuel consumption and average air emissions for all vehicles at all movements will be used to analyze and compare the performance of each intersection design.

\section{Analysis and Results}

\section{1. Balanced Flow Conditions}

The balanced flow conditions refer to the volumes that are input equivalent at all approaches. The relationships between approach volume and average delay of all vehicles at all movements for three-leg, signalized three-leg and three-leg with median U-turn intersections, 20\% left-turn and $2 \%$ heavy vehicles are shown in Fig. 4 . It was found that, the average delay increases as the approach volume increases.

The results of the comparison showed that, the conventional signalized three-leg intersection exhibited higher delays than other intersections. Noteworthy is that, the median U-turn (MUT) design exhibited slightly lower delays than conventional three-leg intersection at balanced volume scenarios; up to approximately 1250 veh/ hr/approach. After this volume level, the median U-turn (MUT) design exhibited higher delays than three-leg intersection. Consequently, it can be inferred that, the conventional three-leg intersection will inmost cases perform better than or at least as good as the median U-turn (MUT) design.

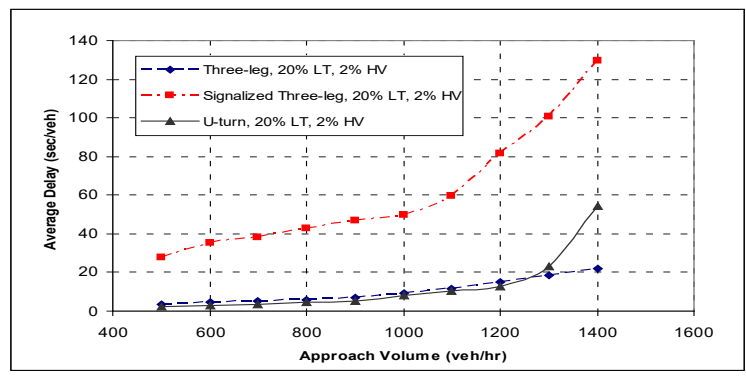

Fig. 4.

Average Delay for all Vehicles at all Movements of Conventional Three-leg, Signalized Three-leg and Median U-turn Designs, 20\% Left-turn, 2\% Heavy Vehicles 
The higher delays of the three-leg with median U-turn (MUT) intersection at balanced volume scenarios after approximately $1250 \mathrm{veh} / \mathrm{hr} /$ approach might be attributed to several factors. The street segments of the main street that extend from the cross street to the U-turn crossovers

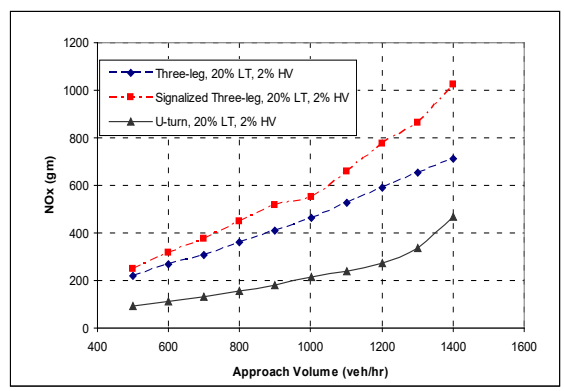

(a) $\mathrm{CO}$

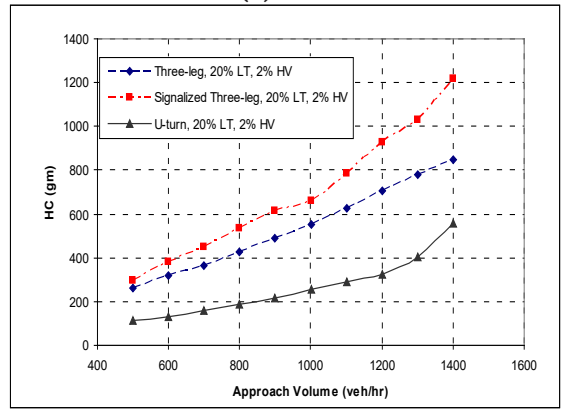

Fig. 5.

(c) $\mathrm{HC}$ carry much higher traffic volumes, compared to three-leg intersection, and are more likely to be oversaturated. Not only the volumes are higher, but they also weave. Another reason for the higher delays of the median U-turn (MUT) design is that the U-turn crossovers are composed of single lanes.

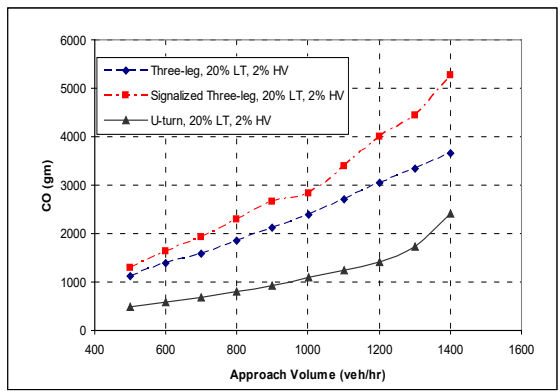

(b) $\mathrm{NO}_{\mathrm{v}}$

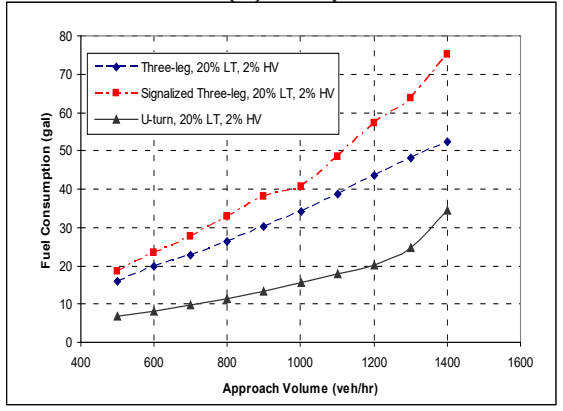

(d) Fuel Consumption

Average Different Emissions and Average Fuel Consumption for all Vehicles at all Movements of Conventional Three-leg, Signalized Three-leg and Median U-turn Designs, 20\% Left-turn, 2\% Heavy Vehicles

Whereas Fig. 5 presents the relationship between approach volume, average air emissions and fuel consumption of all vehicles at all movements for conventional three-leg, conventional signalized threeleg and median U-turn intersections, $20 \%$ left-turn and $2 \%$ heavy vehicles. It can be noticed that, as in this figure, the average air emissions and fuel consumption increase as the approach volume increases. The results of the comparison showed that, the median U-turn (MUT) design exhibited lower air emissions and fuel consumption than other intersections at all balanced volume scenarios. Noteworthy is that, the differences in air emissions between different intersections are minor at low volumes, up to about $1000 \mathrm{veh} / \mathrm{hr} / \mathrm{approach}$. After this 
volume level, the differences in air emissions become more significant.

\subsection{Impact of Left-Turn Percentage on Performance of Median U-Turn Design}

Two different splits of left-turn volumes were analyzed; $20 \%$ and $30 \%$ of the total approach volume, to quantify the impact of increasing the percentage of left-turn traffic on average delay, average air emissions and average fuel consumption of all vehicles at all movements for median U-turn design.
Fig. 6 presents the relationship between approach volume and average delay of all vehicles at all movements for median U-turn design for different balanced volume levels, $2 \%$ heavy vehicles and the two left-turn splits. It was noticed that, as in Fig. 6, the increasing of left-turn traffic percentage always generated higher average delays. The impact of increasing left-turn percentage on the average delay is minor at low volumes, up to about $1100 \mathrm{veh} / \mathrm{hr} /$ approach. After this volume level, the difference in average delay becomes more significant.

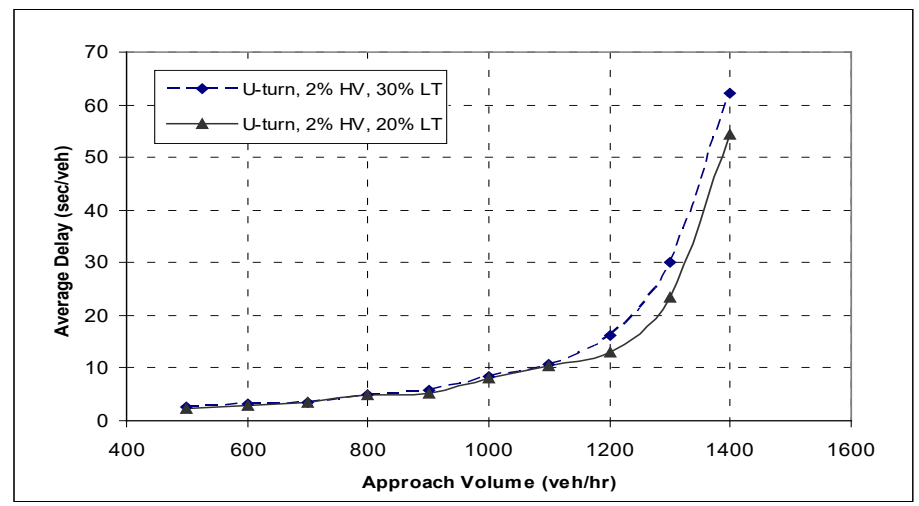

Fig. 6.

Impact of Increasing Left-turn Percentage on Average Delay of all Vehicles at all Movements for Median U-turn Design under Balanced Scenarios, 2\% Heavy Vehicles

Whereas the relationships between approach volume and average air emissions and fuel consumption of all vehicles at all movements for median U-turn design for different balanced volume levels, $2 \%$ heavy vehicles and the two left-turn splits are shown in Fig. 7. It was found that, increasing the percentage of left-turn traffic always generated higher air emissions and fuel consumption. The impact of increasing left-turn percentage on the different air emissions and fuel consumption is significant at low volumes, up to about 1200 veh/hr/approach. After this volume level, the differences in different air emissions become more minor. 


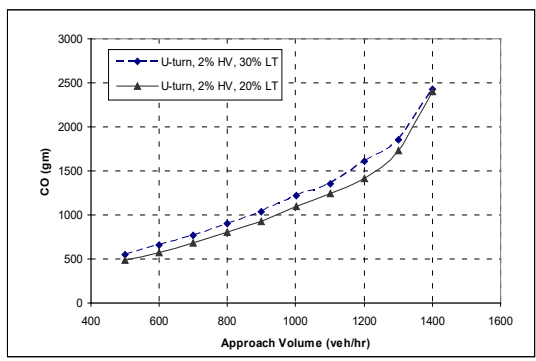

(a) $\mathrm{CO}$

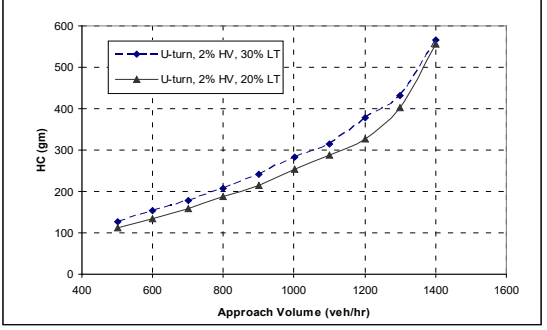

Fig. 7.

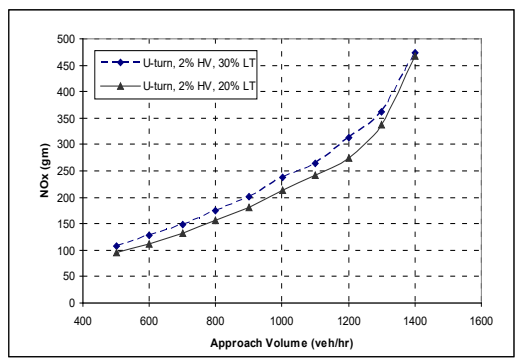

(b) $\mathrm{NO}_{v}$

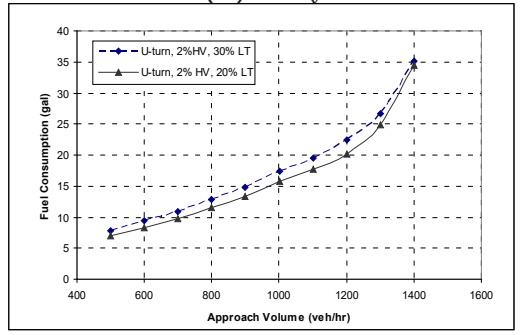

(d) Fuel Consumption

Impact of Increasing Left-turn Percentage on Average Different Emissions and Average Fuel Consumption of all Vehicles at all Movements for Median U-turn Design under Balanced Scenarios, 2\% Heavy Vehicles

\subsection{Impact of Heavy Vehicles Percentage on Performance of Median U-Turn Design}

To quantify the impact of increasing the percentage of heavy vehicles traffic on average delay, average air emissions and fuel consumption of all vehicles at all movements for median U-turn design, two different percentages of heavy vehicles were analyzed; $2 \%$ and $5 \%$ of the total approach volume.

Fig. 8 illustrates the relationship between approach volume and average delay of all vehicles at all movements for median U-turn design for different balanced volume levels, $20 \%$ left-turn and the two heavy vehicles percentages. From Fig. 8, the impact of increasing heavy vehicles percentage on the average delay is minor at low volumes, up to about $800 \mathrm{veh} / \mathrm{hr} /$ approach. After this volume level, the difference in average delay becomes more significant.

Whereas Fig. 9 shows the relationship between approach volume, average air emissions and fuel consumption of all vehicles at all movements for median U-turn design for different balanced volume levels, $20 \%$ left-turn and the two heavy vehicles percentages. It was found that, the impact of increasing heavy vehicles percentage on the different air emissions and fuel consumption is minor at low volumes, up to about $800 \mathrm{veh} / \mathrm{hr} / \mathrm{approach}$. After this volume level, the differences in different air emissions and fuel consumption become more significant. 


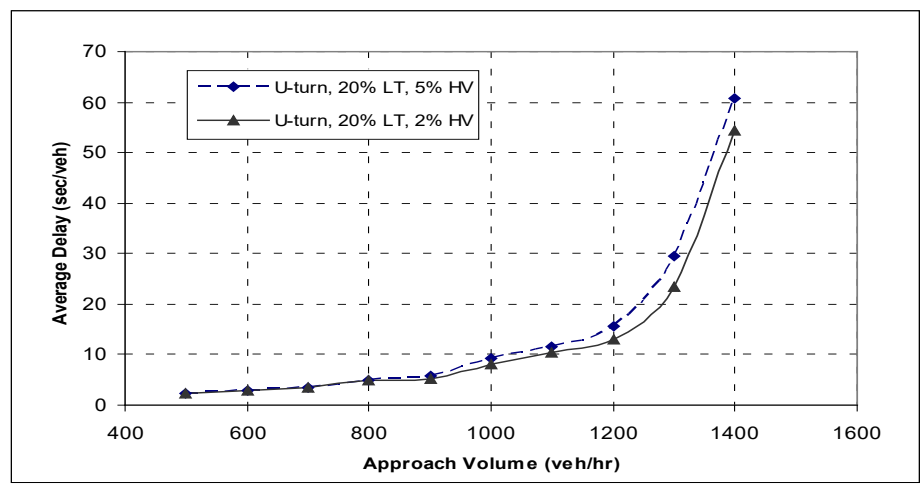

Fig. 8.

Impact of Increasing Heavy Vehicles Percentage on Average Delay of all Vehicles at all Movements for Median U-turn Design under Balanced Scenarios, 20\% Left-turn

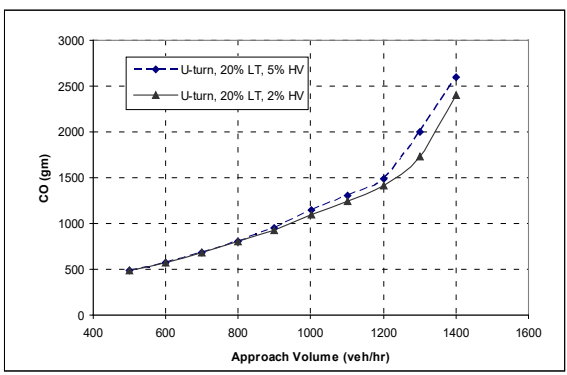

(a) $\mathrm{CO}$

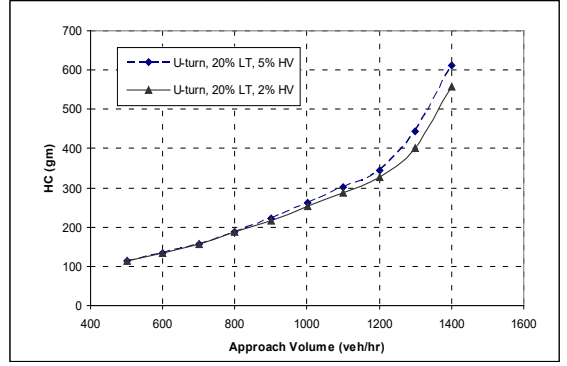

(c) $\mathrm{HC}$

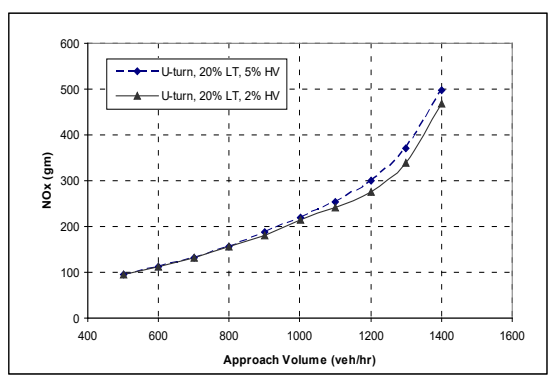

(b) $\mathrm{NO}_{\mathrm{v}}$

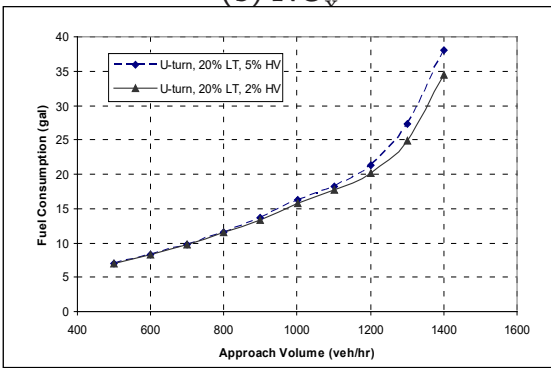

(d) Fuel Consumption

Fig. 9.

Impact of Increasing Heavy Vehicles Percentage on Average Different Emissions and Average Fuel Consumption of all Vehicles at all Movements for Median U-turn Design under Balanced Scenarios, 2\% Heavy Vehicles 


\subsection{Unbalanced Flow Conditions}

The unbalanced flow conditions refer to the volumes that are input not equally distributed at all approaches. The U-turn crossovers were placed in major road. They were plotted for all volume scenarios at $20 \%$ left-turn traffic split and $2 \%$ heavy vehicles. Fig. 10 illustrates the average delay of all vehicles at all movements for threeleg with median U-turn intersection under unbalanced volumes. As shown in Fig. 10, it can be noticed that, the intersection delay increased with the increase of main and/or cross road volumes. Whereas from Fig. 11 shows the average air emissions and fuel consumption of all vehicles at all movements for three-leg with median U-turn intersection under unbalanced volumes. As shown in this figure, it is clear that, air emissions and fuel consumption increased with the increase of main and/or cross road volumes.

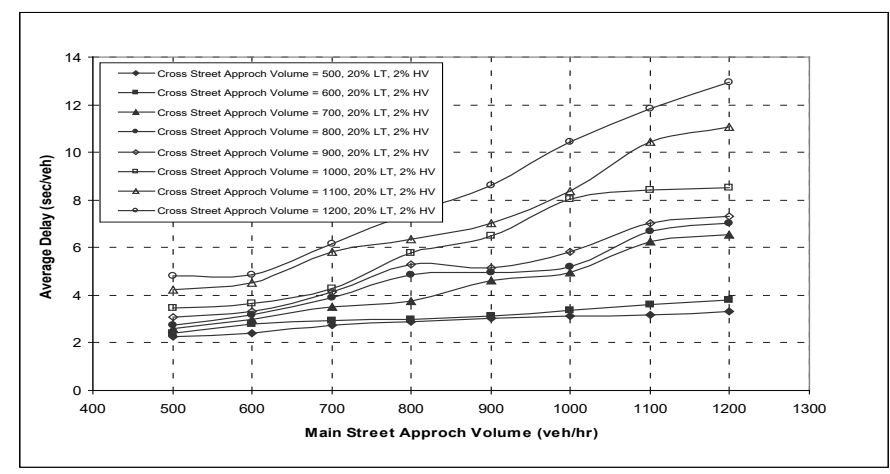

Fig. 10.

Average Delays of All Vehicles at all Movements for Median U-turn Design under Unbalanced Volumes, 20\% Left-turn, 2\% Heavy Vehicles

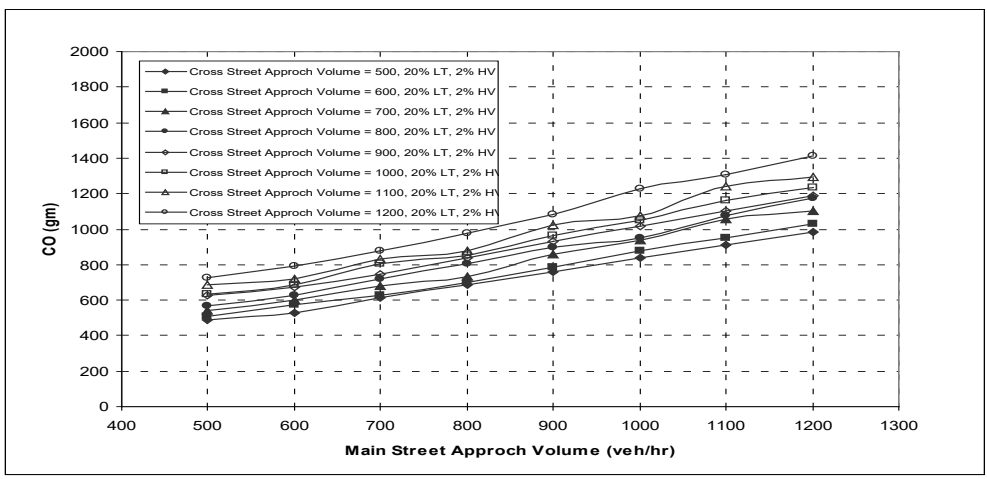

(a) $\mathrm{CO}$ 


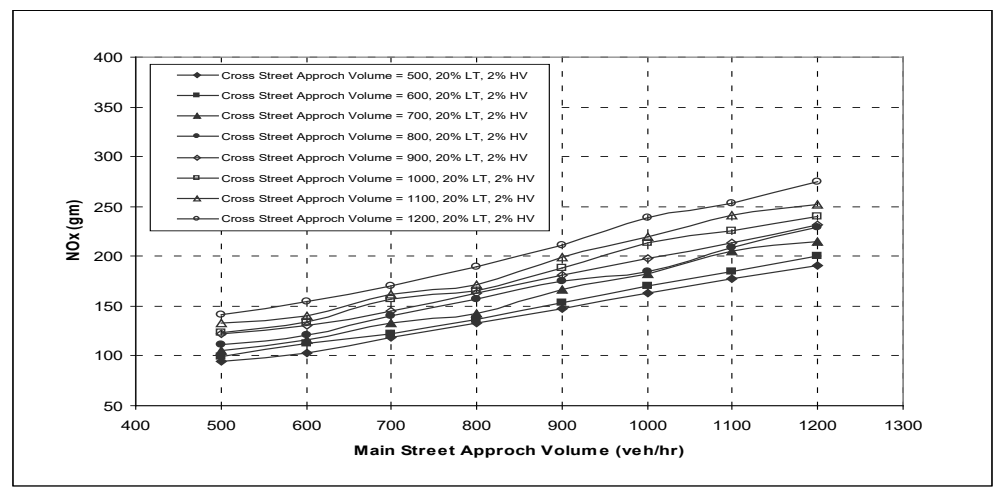

(b) $\mathrm{NO}_{\mathrm{X}}$

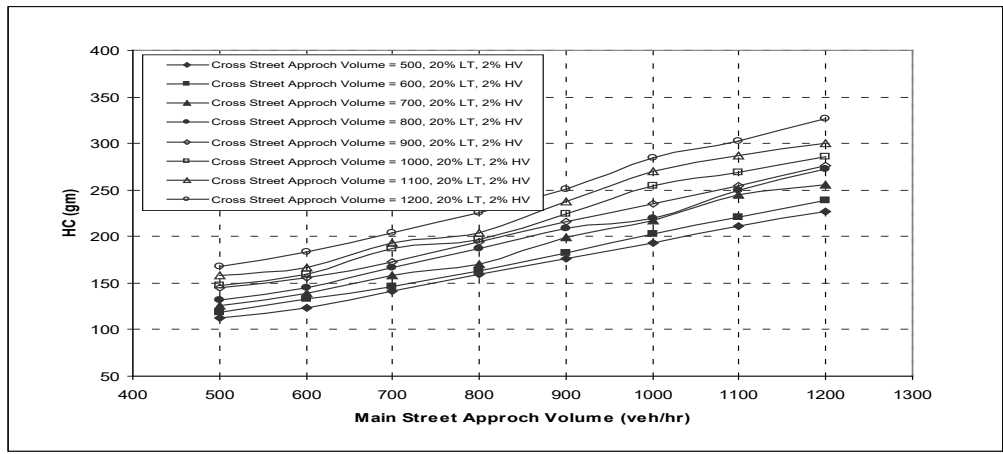

(c) $\mathrm{HC}$

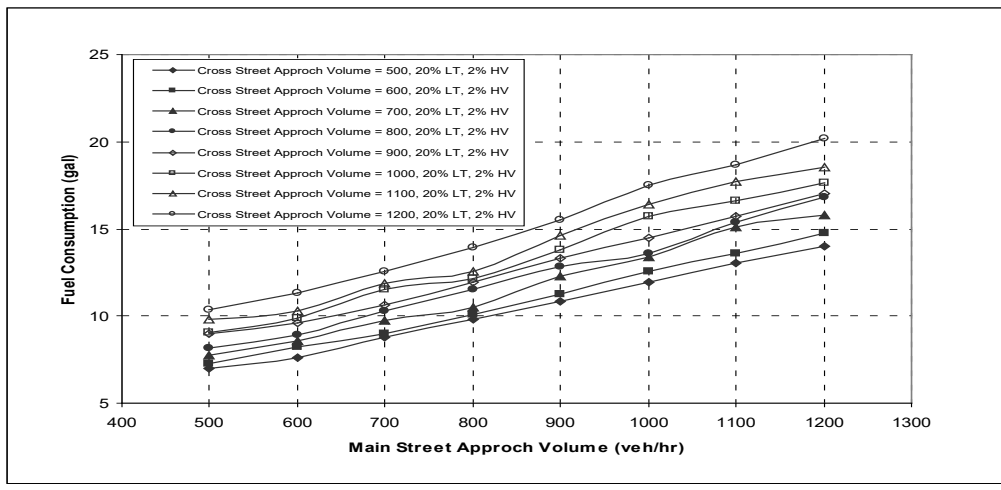

(d) Fuel Consumption

Fig. 11.

Average Different Emissions and Average Fuel Consumption of All Vehicles at all Movements for Median U-turn Design under Unbalanced Volumes, 20\% Left-turn, 2\% Heavy Vehicles 


\section{Conclusions and Recommendations}

This paper describes the impact of median U-turn (MUT) design on average delay and vehicle air emissions. The operational and environmental performance of median U-turn (MUT) design was analyzed under a wide range of traffic volume scenarios using micro-simulation. The analysis was carried out using VISSIM software. Three major types of vehicle emissions were estimated; carbon monoxide (CO), oxides of nitrogen $\left(\mathrm{NO}_{\mathrm{x}}\right)$ and hydrocarbons $(\mathrm{HC})$, also vehicle fuel consumption was estimated. A conventional three-leg intersection and signalized three-leg intersections with similar geometries were also modeled and compared to the three-leg with median U-turn (MUT) intersection. The comparison criteria were the average delay, average air emissions and average fuel consumption of all vehicles at all movements for every intersection design. Analysis showed that:

1. According to relationship between approach volume and average delay of all vehicles at all movements, the median U-turn (MUT) design was shown beneficial only at balanced volume scenarios, up to approximately 1250 veh/hr/approach.

2. In general, the median U-turn (MUT) design was shown beneficial according to relationship between approach volume, average air emissions and fuel consumption.

3. For the median U-turn (MUT) design, the increasing of left-turn traffic percentage always generated higher average delays, air emissions and fuel consumption of all vehicles at all movements.

4. For the median U-turn (MUT) design, the impact of increasing heavy vehicles percentage on average delay, air emissions and fuel consumption is minor at low volumes, up to about 800 veh/hr/approach. After this volume level, the differences become more significant.

5. Under unbalanced volume scenarios, the average delay, air emissions and fuel consumption increase with the increase of main and/or cross street volumes for the median U-turn (MUT) design.

It can be concluded that, the operational performance of three-leg with median U-turn (MUT) design is good at balanced volume scenarios, up to approximately 1250 veh/hr/approach. Also, the environmental performance of three-leg with median U-turn (MUT) design is good at all traffic volume scenarios in comparison to conventional three-leg intersection and signalized three-leg intersections. In addition, under unbalanced volume scenarios, the average delay, air emissions and fuel consumption increase with the increase of main and/or cross street volumes for the median U-turn (MUT) design.

A future extension of this work will include obtaining field data in order to verify the results obtained from VISSIM using emissions detection instrument.

\section{References}

Bared, J. G.; Kaisar, E. I. 2002. Median U-turn Design as an Alternative Treatment for Left Turns at Signalized Intersections, ITE Journal 72(2): 50-54.

El-Esawey, M.; Sayed, T. 2011. Operational Performance Analysis of the Unconventional Median U-turn Design Using Micro-simulation. Proceedings of the Transportation Research Board $90^{\text {th }}$ Annual Meeting, Washington, DC. 
El-Metwally, M.; Rakha, H. 2009. Analysis of Capacity Drop at Congestion toward Better Environment. International Road Federation. Retrieved September 15, 2015, from http://www.irfnews.org/files/pdfs/ Analysis_of_Capacity_Drop_at_Congestion_toward_ Better_Environment.pdf

Environmental Protection Agency 1975. Guidelines for Air Quality Maintenance Planning and Analysis. Volume 9, Evaluating Indirect Sources. Environmental Protection Agency, Washington, D.C.

Gyawali, S. 2014. A New Decision Making Approach for Indirect Left Turn Treatments by Utilizing Decision Assistance Curves. Ph.D. Degree Thesis, Faculty of The Graduate College, University of Nebraska, Lincoln. 80-94.

Highway Capacity Manual 2010. TRB, National Research Council, Washington, D.C.

Liao, Y.; Machemehl, B. 1995. Fuel Consumption Based Optimal Traffic Signal Timing, 37 th $T R F$ Annual Meeting Proceedings, 527-544.

Lv, J. 2012. Signal Timing Optimization to Improve Air Quality. Ph.D. Thesis, Office of Graduate Studies, Texas A \& M University, USA, 1-15.

Mandavilli, S.; Rys, M.J. 2008. Russell, E.R. Environmental Impact of Modern Roundabouts, International Journal of Industrial Ergonomics 38 (2): 135 142.

Midurski, T.; Corbin, V. 1976. Characterization of Washington, D.C., Carbon Monoxide Problem. GCA Corporation, Environmental Protection Agency, Washington, D.C.

Mustafa, S.; Mohammed, A., Vougias, S. 1993. Analysis of Pollutant Emissions and Concentrations at Urban Intersections. Institute of Transportation Engineers, Compendium of Technical Papers.
Niittymaki, J.; Hoaglund, P.G., 1999. Estimating Vehicle Emissions and Air Pollution Related to Driving Patterns and Traffic Calming. In Proceedings of Urban Transport Systems conference, Lund, Sweden.

Olarte, C. 2011. Operational and Environmental Comparisons between Left-turn Bypass, Diverging Flow and Displaced Left-turn Intersection Designs. Master Degree thesis, College of Engineering and Computer Science, Florida Atlantic University, USA, 1-11.

PTV, 2014. VISSIM 7.00 User Manual. Planning Transport Verkehr, Karlsruhe.

Rodegerdts, L.; Nevers, B.; Robinson, B. 2004. Signalized Intersections. Informational Guide. Publication FHWA-HRT-04-091. FHWA, U.S. Department of Transportation, 244.

Srinivasan, R.; Subramaniam, S. 1979. Automobile and Air Pollution, Indian Highways. Indian Roads Congress, New Delhi, 7 (12): 27-39.

Taha, M.; Abdelfatah, A. 2015. Impact of U-Turns as Alternatives to Direct Left-Turns on the Operation of Signalized Intersections, Journal of Traffic and Logistics Engineering 3 (1): 12-17.

Tarnoff, P.; Parsonson, P. 1979. Guidelines for Selecting Traffic Signal Control at Individual Intersections. National Cooperative Highway Research Program, Transportation Research Board, National Research Council, Washington, D.C.

Varhelyi, A. 2002. The Effects of Small Roundabouts on Emissions and Fuel Consumption: A Case Study, Transportation Research Part D: Transport and Environment 7(1): 65-71.

Yang, X.; Zhou, H. 2004. CORSIM-Based Simulation Approach to Evaluation of Direct Left Turn versus Right Turn Plus U-Turn from Driveways, Journal of Transportation Engineering ASCE 130 (1): 68- 75. 